\title{
Investigation of orthologous pathogen recognition gene- rich regions in Solanaceous species
}

\begin{tabular}{|r|l|}
\hline Journal: & Genome \\
\hline Manuscript ID & gen-2016-0217.R2 \\
\hline Manuscript Type: & Article \\
\hline Date Submitted by the Author: & 04-Jul-2017 \\
\hline Complete List of Authors: & $\begin{array}{l}\text { Di Donato, Antimo; University of Naples, Department of Agricultural } \\
\text { Science } \\
\text { Andolfo, Giuseppe; University of Naples, Department of Agricultural } \\
\text { Science } \\
\text { Ferrarini, Alberto; Universita degli Studi di Verona, Department of } \\
\text { Biotecnology } \\
\text { Delledonne, Massimo; University of Verona } \\
\text { Ercolano, Maria Raffaella; University of Naples, }\end{array}$ \\
\hline Is the invited manuscript for \\
consideration in a Special \\
Issue? :
\end{tabular}

\section{SCHOLARONE ${ }^{\text {w }}$ \\ Manuscripts}




\section{Investigation of orthologous pathogen recognition gene-rich regions in}

\section{Solanaceous species}

3

4

Di Donato A. ${ }^{1}$, Giuseppe A. ${ }^{1}$, Ferrarini A. ${ }^{2}$, Delledonne M. ${ }^{2}$, Ercolano M.R. ${ }^{{ }^{*}}$

5

6

${ }^{1}$ Dipartimento di Agraria, Università di Napoli ‘Federico II’, Via Università 100, 80055 Portici, Italy.

7

${ }^{2}$ Dipartimento di Biotecnologie, Università degli Studi di Verona, Strada le Grazie, 15, 37134 Verona, Italy

8

9

10

11

12 AD: antimo.didonato3@gmail.com

13 GA: giuseppeandolfo@hotmail.com

14 AF: alberto.ferrarini@univr.it

15 MD: massimo.delledonne@univr.it

16 MRE: ercolano@unina.it

17

18

19

20

21

22

23

Corresponding author:

24

25

Ercolano Maria Raffaella

26

27

Dipartimento di Agraria, Università di Napoli ‘Federico II’, Via Universita` 100, 80055 Portici, Italy.

Tel/Fax +390812539431 
31 Abstract

32

33 Pathogen receptor proteins such as receptor-like protein (RLP), receptor-like kinase (RLK) and nucleotide-binding leucine-rich repeat (NLR) play a leading role in the plant immunity activation.

The genome architecture of such genes was extensively investigated in several plant species. However, we still know little about their elaborate reorganization arose during the plant speciation process. Using recently released pepper and eggplant genome sequences we were able to identify 1097 pathogen recognition genes (PRGs) in pepper Zunla-1 and 775 in eggplant Nakate-Shinkuro. The retrieved genes were analysed for their tendency to cluster, using different methods to infer the means of grouping. Orthologous relationships among clustering loci were found, and interesting reshuffling within given loci was observed for each analysed species. The information obtained were integrated in a comparative map to highlight the evolutionary dynamics in which the PRG loci were involved. Diversification of 14 selected PRG-rich regions was also explored using a DNA target-enrichment approach. A large number of gene variants was found as well as rearrangements of single protein domain encoding sequences and changes in chromosome gene order among species. Gene duplication and transposition activity have clearly influenced plant genome R-gene architecture and diversification. Our findings contribute to addressing several biological questions concerning the parallel-evolution occurred between genomes of Solanaceae family. Moreover, the integration of different methods proved a powerful approach to reconstruct the evolutionary history in plant families and to transfer important biology findings among plant genomes.

Keywords: Pathogen recognition genes; Capsicum annuum; Solanum melongena; gene arrangements; target sequencing. 
55

56

57

58

59

60

61

62

63

64

65

66

67

68

69

70

71

72

73

\section{Introduction}

The Solanaceae family comprises more than 3,000 species and includes major food crops such as tomato (Solanum lycopersicum), potato (Solanum tuberosum), eggplant (Solanum melongena) and pepper (Capsicum annuum). In recent years, several important Solanaceae species have been sequenced (Fernandez-Pozo et al. 2015) and wild species genomes investigated by sequencing and resequencing (Qin et al. 2014, Aflitos et al. 2014, Aversano et al. 2015). Solanaceae species have also served as ideal systems for studying the genetics and molecular basis of plant resistance mechanisms (Ercolano et al. 2012). Given the lack of extensive studies on the eggplant and pepper genomes regarding pathogen recognition genes (PRGs: RLP - receptor-like protein, RLK - receptorlike kinase and NLR - nucleotide-binding leucine-rich repeat), information gathered from other species can be used to steer investigation in such species.

According to comparative genomic studies, Solanaceous species share extensive syntenic regions (Wang et al. 2008): many of the loci involved in disease resistance in tomato have putative orthologues, in potato, eggplant and pepper in corresponding positions (Grube et al. 2000, Vossen et al. 2014). Further characterisations have demonstrated that tomato PRG homologues in potato, tobacco and pepper are subject to dramatic reshuffling (Andolfo et al. 2013a, Seo et al. 2016, Wei et al. 2016).

Comparison of the spatial arrangement of genes in different genomes raises important questions on how complex biological systems evolve and function. Spatial analyses of the orthologous genomic region can unravel selection processes and species history (Hoberman and Durand 2005). Over time the large- and small-scale rearrangements occurring in orthologous loci have shaped the specific genomic architecture of different species (Yeaman 2013). To reconstruct the direction and magnitude of evolutionary trajectories of a given gene family, it is critical to detect the ancient loci that can lead to the formation of gene clusters (Baumgarten et al. 2003, Luo et al. 2012). 
In previous studies PRG clusters were identified using approaches based both on identifying a genomic region containing a number of PRGs or on a set of genes that delimit an interspace (Richly et al. 2002; Hoberman and Durand 2005). A more rigorous investigation of well-known Solanaceae PRG clustered loci dynamics can help to understand how their arrangement can impact diseasespecific responses, since all functional resistance genes found in tomato and potato are included in a cluster (Andolfo et al. 2014). The recently developed target-enriched strategies for next-generation sequencing could facilitate the analysis of PRG-rich regions (Grover et al. 2012). It has already been demonstrated that targeted sequencing can expand our knowledge of PRGs (Andolfo et al. 2014). Furthermore, targeted sequencing of selected PRG loci combined with availability of highquality reference genome sequences can offer insights into the mechanisms of PRGs evolution (Gasc et al. 2016, Steuernagel et al. 2016, Witek et al. 2016). In this work, the annotation of NLRs, RLPs and RLKs coding genes in eggplant and pepper genomes was performed. The PRG clustered loci rearrangement arose was reconstructed using multiple and combined methods, and a genomewide comparative map in the three Solanaceae species was also realised. Finally, Solanaceae loci containing functionally characterised PRGs in such species were explored by targeted sequencing and microsynteny analysis.

\section{Materials and methods}

\section{Pathogen recognition gene family annotation}

A script developed in-house to identify tomato and potato PRG proteins by Andolfo et al. (2013b) was implemented in this study. The HMM profiles were used to screen the pepper and eggplant

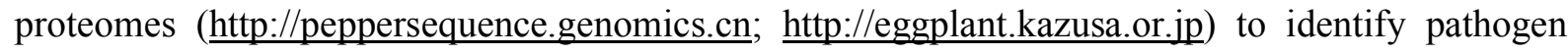
recognition proteins. This proteins set was further analysed using InterProScan v5 (Jones et al. 2014) to verify the presence of characteristic domains of pathogen recognition proteins (CC: coiled coil; NB: nucleotide binding; LRR: leucine rich repeat; TIR: Toll/interleukin-1 receptor; Kin: kinase; eLRR: extracellular-leucine rich repeat; TM: transmembrane). 


\section{Cluster analysis}

106 The calculation of local gene enrichment was conducted using two methods: an arbitrary max gap

107 approach (MG) (Hoberman et al. 2005), for identifying the spatial arrangement of genes with

108 similar functions separated by a gap of no more than eight non-R genes (Richly et al. 2002, Luo et 109 al. 2012); and a sliding window (SW) approach using REEF software

110 (http://telethon.bio.unipd.it/bioinfo/reef/), that is able to identify chromosome regions of a given 111 size that contain a number of adjacent PRGs based on a statistical test on genomic distribution 112 (Coppe et al. 2006). Both analyses were conducted on ITAG Tomato Genome 2.3 113 (http://solgenomics.net) and Zunla-1 Pepper Genome 2.0 (http://peppersequence.genomics.cn). In 114 particular, sliding window scanning was conducted with a setting size of 0.5 and $1 \mathrm{Mb}$, a Q-value of 1150.05 and a shift length of $50 \mathrm{~Kb}$. For both methods, we also varied the minimum gene number cut116 off from two to four genes to highlight the clustering tendency of specific regions.

\section{Targeted sequencing}

119 Targeted sequencing workflow is illustrated in Figure S1. The experiment was executed on four

120 plant species: S. lycopersicum var. Pyrella (Sl-Pyrella), S. peruvianum 10543 (Sp-10543), S.

121 melongena var. Cima Viola (Sm-Cima Viola) and C. annuum 1014 (Ca-1014). Fully expanded

122 leaves were detached from three-week-old greenhouse-grown plants of each accession. Genomic

123 DNA was extracted from young leaf tissue of the same plants, using the DNeasy Plant Mini kit

124 (Qiagen Valencia, USA), following the manufacturer's instructions.

125 A custom-designed SureSelect Target Enrichment Kit (Agilent Technologies, Santa Clara, CA) was

126 used to capture selected regions, according to the manufacturer's instructions. The probe library was

127 designed on 14 selected regions of the ITAG v2.3 genome, identified by Andolfo et al. (2013) for a

128 total of $5.7 \mathrm{Mb}$ (see supplementary material). Library quality was determined using the Agilent

129 High Sensitivity DNA kit on the Agilent 2100 Bioanalyzer. Libraries were pooled at equimolar 
130

131

132

133

134

135

136

137

138

139

140

141

142

143

144

145

146

147

148

149

150

\section{Comparative analysis}

152 Orthology analysis was conducted on proteomes of eggplant (SME_r2.5.1_pep_ip), tomato

153 (ITAG2.3_proteins) and pepper (Capsicum.annuum.L_Zunla-1_v2.0_PEP) using Inparanoid

154 Software and Multiparanoid Software with default parameters (Remm et al. 2001, Alexeyenko et al.

concentrations and sequenced with TruSeq PE Cluster Kit v3 and TruSeq SBS Kit v3 (Illumina, San Diego, CA) on Illumina HiSeq 1000 sequencer (Illumina, San Diego, CA) generating 100-bp paired-end reads.

\section{Mapping and variant calling}

Read mapping was performed using BWA [24] on the reference genomes: ITAG Tomato Genome 2.3 (http://solgenomics.net/) for samples of S1-Pyrella and Sp-10543; draft genome of eggplant v2.5.1 (http://eggplant.kazusa.or.jp) for the Sm-Cima Viola sample; Zunla-1 Pepper Genome 2.0 (peppersequence.genomics.cn) for the Ca-1014 sample. This procedure was executed for all samples with $\mathrm{t}=10$ and default setting. Adapter sequences were removed from sequence reads using Scythe software with default parameters (v. 0.994; https://github.com/vsbuffalo/scythe). Low quality read ends were trimmed using Sickle software (https://github.com/vsbuffalo/scythe). All raw sequences were deposited in the NCBI database with the project number SRP075801.

Variants between four genotypes (S. lycopersicum var. Pyrella, S. peruvianum 10543, S. melongena var. Cima Viola and C. annuum 1014) and reference genomes relative were called using SAMtools software (Li and Durbin 2009) with a minimum read depth threshold of 20. Identified variants were annotated using SnpEff v3.4 (Cingolani et al. 2012) to predict their effect on the genes, using reference genomes annotations. Finally, polymorphisms were subsequently filtered for position, considering only those that were in a synteny block at the region was used for probe design indicated in eggplant and pepper sequencing work (Qin et al. 2014, Hirakawa et al. 2014). 
155 2006). We used a confidence score threshold $=1$ to directly estimate orthology relationships 156 between the identified PRGs.

157 A comparative map was constructed, merging results obtained from PRG prediction, cluster dataset

158 and orthology results using the Circos package (Krzywinski et al. 2009). Eggplant chromosomes

159 were assembled using information reported in Hirakawa et al. (2014). Position and IDs of isolated 160 and studied loci were reported by Andolfo et al. (2013b) and in the Sol Genomics Network portal

161 (https://solgenomics.net/).

162 Nucleotide sequences of clustered PRGs in genomic sequenced regions 4 and 10 were extracted 163 from genomes and aligned using EINS-i algorithm of MAFFT (Katoh and Standley 2013) software.

164 The procedure was performed separately for receptor-like proteins (RLP and RLK) and NLR genes 165 coding; sequences with low global alignment identity $(<25 \%)$ were discarded. The phylogenetic 166 relationships of predicted Solanaceae PRGs were inferred separately for each structural class (e.g. 167 NLRs, RLPs) using MEGA 6 software with the maximum likelihood method general time 168 reversible model. The bootstrap consensus tree of 100 replicates was taken to represent the 169 evolutionary history of the sequences analysed (Tamura et al. 2013). Transposable elements were 170 found using BLASTn search (Camacho et al. 2009) on library of transposable element reported on 171 Pepper Genome Database (http://peppersequence.genomics.cn/page/species/download.jsp), and 172 they were aligned aligned. Specific gene and protein alignments were generated in Geneious R6 173 platform (Kearse et al. 2012).

\section{Results}

176 Chromosome distribution of pepper and eggplant pathogen recognition genes

177 A total of 1097 and 775 pathogen recognition genes were identified in C. annuum Zunla-1 (Zun) 178 and S. melongena Nakate-Shinkuro (Nak) genomes, respectively (Supplementary Table1). The 179 chromosome distribution of PRG classes retrieved in the two analysed species in comparison with 180 the tomato PRGs profile obtained by Andolfo et al. ( 2013b) is shown in Figure 1. The total number 
181 of genes varied along the chromosomes of each species. Chromosome 4 was enriched in PRGs both

182 in tomato and pepper (94 vs 129), whilst the highest number of genes in eggplant was observed on

183 chromosome 11. A large variation in genome arrangement was observed for the assessed classes in

184 pepper and eggplant. The RLK class showed the largest variation in pepper, ranging from the 78

185 members on chromosome 4 to 9 members on chromosome 10. Instead, eggplant showed a similar

186 RLP (3 to 24) and RLK (8 to 25) trend distribution. NLR path distribution showed marked

187 differences between the two species: in pepper a conspicuous number of NLR-related genes were

188 identified on chromosomes 3 (43) and 5 (34), whilst in eggplant they are enriched on chromosome

18911 (45). Eggplant and pepper genomes also displayed a large number of PRGs (157 and 173

190 respectively) located on chromosome 0, which could lead to a bias in genome distribution

191 (Supplementary Table 2).

192

193

\section{Identification of resistance orthologous groups}

194 To translate the resistance gene information from the tomato model species to other Solanaceae 195 crops, we performed an orthology prediction analysis (Supplementary Table 3). The three species

196 shared a core set of 320 selected as bona fide resistance orthologous groups (ROGs) (Figure 2), 197 including a total of 1076 PRG proteins, of which 182 were RLP, 297 NLR and 498 RLK. In 198 common ROGs a larger number $(89,95)$ of PRG paralogues were shared between $C$. annuum and $S$.

199 lycopersicum. Furthermore, 91 ROGs were only shared between tomato and pepper genomes and 20067 between tomato and eggplant. The Orthology analysis also allowed ortho-groups containing 201 homologues of cloned genes. Six very important Solanaceae $R$-gene loci (Cf9, Hero, Prf, Tm2 and 202 Mi1.2) showed a highly confident orthologue in each three species analysed (Supplementary table 203 3). Two orthologues to tomato LeEIX1 and LeEIX2 homologues (Solyc07g008620 and 204 Solyc07g008630) were identified in pepper and eggplant genomes (Capana00g004962 and 205 Sme2.5_01783.1_g00006). The tomato RpiBlb1 homologous gene (Solyc08g076000) presented 206 two and one orthologues in pepper eggplant genomes, respectively (Capana01g000864 and 
207 Capana01g000870; Sme2.5_11213.1_g00002.1). Ve2 gene presented only two orthologues in 208 tomato and pepper genomes (Solyc09g005080; Capana09g001153). Interestingly, a large 209 diversification of I2 homologous genes was found in tomato and eggplant genomes. The I-2 gene 210 homologues (Solyc11g071430- Solyc11g071420), located on chr11, showed several paralogues, 211 including a tomato LRR gene (Solyc11g065800) similar to Capana11g000417 and 212 Sme2.5_15564.1_g00001.

213 Other tomato genes implicated in the resistance process, but not included in the principal four 214 pathogen recognition protein classes, showed an orthologous relationship in pepper and eggplant 215 genome. For example, ASC-1, located on chromosome 3, (locus name Solyc03g114600) is in the 216 same group as Capana03g000932 and Sme2.5_04467.1_g00005, and the Mlo1 gene (locus name 217 Solyc04g049090) showed orthologues both in pepper and eggplant (Capana05g002411, 218 Capana06g001935, Capana11g000102, Sme2.5_00266.1_g00009, Sme2.5_12945.1_g00001).

\section{Detection of genomic regions rich in pathogen recognition genes}

221 In order to investigate the genomic arrangement of pathogen recognition loci and to evaluate the 222 grouping tendency of such genes in tomato and pepper genomes, we performed both a sliding223 window (SW) scan and max-gap (MG) analysis. The eggplant genome was not included in this 224 analysis since its genome is assembled partially.

225 Taking into account the structural differences of the compared genomes, SW scanning was 226 performed on a window of 0.5 or $1 \mathrm{Mb}$, varying the minimum gene number cut-off from two to four 227 genes (Table 1). The window of 0.5 Mb was set up based on size of super-clusters detected from 228 Andolfo et al. (2013b) and it has been extended up to $1 \mathrm{Mb}$ considering the larger size of pepper 229 genome.

230 Tomato displayed from 39 to 66 clusters, with a number of genes varying from 5.6 to 6.9. The 231 number of PRG clusters, as well as the number of genes included in a cluster, showed a higher 232 variation in pepper, ranging from 106 to 59 and to 7 to 10 , respectively. Using the MG method, we 
233 were able to identify from 40 to 146 clusters in tomato, with the number of genes per cluster

234 varying from 3.2 to 5.7, and from 201 to 72 in pepper, with the number of genes per cluster varying

235 from 3.9 to 6.6 (Table 1). The SW and MG analyses differ in the number of clusters identified and

236 the number of genes included in a single cluster. In general, the average size $(\mathrm{Kb})$ of tomato clusters

237 using MG was lower than in SW. The higher data point match was obtained by using three genes

238 per cluster as a cut-off both for MG and SW (with a sliding window setting of $0.5 \mathrm{Mb}$ for tomato

239 and $1 \mathrm{Mb}$ for pepper). In particular, 23 and 57 clusters in tomato and pepper, respectively, showed

240 exactly the same matching genes. Total MG and SW cluster-datasets were filtered for the presence

241 of at least two orthologues among the analysed species. Following this criterion, we detected four

242 tomato clusters shared with pepper identified only by the MG approach and three clusters identified

243 only by the SW approach. Therefore, to avoid data loss, we merged MG and WM data to obtain a

244 list of conserved Solanaceae PRG clusters (Table 2 and Supplementary Table 4).

\section{Comparative analysis of Solanaceae PRG groups}

247 A comparative genomic map was obtained by merging the results obtained by PRG prediction 248 (2632 PRGs), with cluster analysis results filtered for orthology (176 clusters) (Supplementary

249 Table 2; Figure 3). PRG arrangement data of eggplant draft genome were computed by looking at 250 least at two adjacent genes on a single scaffold. In $S$. melongena 86 PRG groups with an average 251 size of $\sim 22 \mathrm{Kbp}$ were recorded. Seventeen tomato, 21 pepper and 22 eggplant clusters shared at 252 least one PRG orthologue among all three species. Furthermore, 23 tomato clusters shared PRGs 253 exclusively with 34 pepper clusters, and exclusively with five eggplant clusters. In particular, the 254 Cf4/Cf9 locus (tomato chromosome 1) showed orthologous genes in eggplant and pepper syntenic 255 regions. Four PRG clusters detected on tomato chromosome 4 shared orthologous-PRG located on 256 chromosome 5 and 11 in pepper and eggplant, respectively. In particular, Hero cluster share 257 orthologous genes with a pepper cluster on chromosome 5. Two tomato clusters, located on 258 chromosome 5 and containing BS4 gene and homologue R1 genes (Solyc05g007350, 
259 Solyc05g007610, Solyc05g007630 and Solyc05g007640), shared orthologous clustered genes on

260 pepper chromosome 5. A tomato cluster on chromosome 5 (Solyc05g006570, Solyc05g006620, 261 Solyc05g006630 and Solyc05g006670) is highly conserved in the pepper and eggplant genome. 262 Clusters Pto and Prf shared orthologous genes with clusters located on pepper chromosomes 9 and 263 11. Clusters LeEix1 and LeEIX2 located on chromosome 7 showed orthology with a cluster on the 264 corresponding chromosome in pepper. A tomato cluster containing Rblb1 homologues on 265 chromosome 8 shares orthologous genes with clusters located on pepper chromosome 1 and 266 eggplant chromosome 3. PRG organised in clusters on chromosome 9 have orthologues on pepper 267 chromosome 3. Clusters Tm2 and Sw5 showed orthologous clusters on the corresponding 268 chromosome in pepper. The I2 clusters located on tomato chromosome 11 showed orthologous 269 clusters on chromosome 11 of eggplant and pepper. The tomato cluster flanked by Gpa2 markers 270 showed orthologous clustered genes on pepper chromosome 9.

\section{Sequence diversity in selected PRG orthologous loci}

272 Fourteen orthologous loci of tomato, eggplant and pepper cultivated species (S. lycopersicum var. 273 Pyrella: Sl-Pyrella; S. melongena var. Cima Viola: Sm-Cima Viola; C. annuum 1014: Ca-1014) and 274 of a wild tomato species (S. peruvianum 10543: Sp-10543), were re-sequenced using a targeted 275 sequencing approach (Figure S1). A total of 33542210, 30949590, 32242713 and 33888476 276 sequencing reads were generated for Sl-Pyrella, Sp-10543, Sm-Cima Viola and Ca-1014, 277 respectively (Supplementary Table 5). Using this approach, we analysed the evolutionary dynamics 278 of 14 selected regions containing PRGs putatively implicated in plant disease resistance.

279 The size of genomic regions captured and the number of reads mapping to the reference genomes 280 are reported in Table S5. In each region, a large number of homologous genes to cloned resistance 281 genes was found. The reads mapped on the respective genomic regions ranged from 17487130 to 2829500772 in cultivated and wild tomatoes and from 11005089 to 1651126 in Ca-1014 and Sm-Cima 283 Viola. All variants obtained with respect to the reference gene annotations were filtered for genome 
284

285

286

287

288

289

290

291

292

293

294

295

296

297

298

299

300

301

302

303

304

305

306

307

308

position, taking into account only those that were in the regions used for the probe design in pepper and eggplant syntenic regions. The number of variants identified in the analysed regions ranged from 101579 to 1484 . The S. peruvianum (Sp-10543) sample showed the highest number of variants (Supplementary Table 6), since the reads are mapped to the heterologous S. lycopersicon "Heinz 1706" genome. Ca-1014 also showed a larger quantity of variants $(6,930)$, perhaps due to the greater length of syntenic regions (Supplementary Table 5). The I2 region showed a high level of diversification in all species. In tomato regions 1,2 and 9 also showed a conspicuous variation. In Sp-10543, five regions (1, 3, 4, 5 and 13) showed a number of variants up to 8000. In Sl-Pyrella and in eggplant, detected variants were nearly all homozygotes (88.8\% and 97.7\%) (Figure S2), while most of the wild tomato variants were heterozygotes (58.1\%). Sl-Pyrella showed the highest percentage of INDELs with $33.83 \%$ of insertions and $9.55 \%$ of deletions (Figure S3). When compared to the corresponding annotated genomes, we observed a significantly higher polymorphism frequency in intergenic regions than in genic regions for all species except for SmCima Viola (9.23\%), which was the only sample with reads mapped on a draft genome (Table 2). In all, 72, 9468, 80 and 243 variants of different types were detected on PRG genomic loci in S1Pyrella, Sp-10543, Sm-Cima Viola and Ca-1014, respectively (Table 3).

\section{Microsyntenic PRG region reshuffling}

The tomato PRG target region 4, located on chromosome 5, containing one RLP, one RLK and two TNLs, is highly conserved in pepper and eggplant (Figure 4). Orthologous genes in pepper show the same tomato order and orientation, except for an inversion occurring between Capana11g001503 and Capana11g001504 (Figure 4). By contrast, in eggplant a first inversion was observed between genes 1 and 3 ( 7 and 8 in tomato) and a second inversion between genes 1 and 2 (6 and 8 in tomato). Pepper genes 12 and 13 were orthologous to tomato loci 7 and 8, but unlike the latter, do not encode the TIR domain (Figure 4, panel a).. The Solyc05g006620 gene in pepper was divided into Capana11g001502 and Capana11g001503, probably due to a transposable element insertion, as 
309 showed in Figure 4, panel d. In eggplant changes in the protein structure of

310 Sme2.5_04766.1_g00001 were recorded. Moreover, three missense SNP variants on gene

311 Sme2.5_04766.1_g00001 and one gene Sme2.5_04766.1_g00005 were identified by targeted 312 sequencing in the Sm-Cima Viola accession (Figure 4, panel a). The coding region of Sme

313 2.5_05725.1 g00001 displays six non-synonymous mutations. Non-synonymous mutations were

314 also identified in coding regions of Capana11g001503 and Capana11g001504 in the C. annuum

3151014 genome. Instead, PRGs in this region were highly conserved in tomato (Pirella vs Heinz 316 1706).

317 The tomato target region 10, including a PRG cluster, located on chromosome 8 also showed a good 318 level of collinearity with the pepper and eggplant genome. Figure 5 (panel a) presents the region 319 flanked by the marker est_ae501f12. This cluster in tomato consists of three RLKs, three CNLs and 320 one NL, genes that are split into two clusters in pepper, separated by a third cluster without 321 orthologous genes. An inversion was observed between tomato genes 5, 6, 11 and pepper genes 14, 32219 and 20. The tomato gene 7 was originated by tandem duplication of gene 6 (Figure 5, panel a 323 and c). Discordant results were indicated in phylogenetic analysis and nucleotide sequence 324 alignment due to a large TE insertion on the intron of Capana01g00870 (Figure 5, panel d). Gene 20 325 coding an RLP protein showed partial orthology with an RLK gene in tomato. A similar occurrence 326 was found for the NLR gene 14, lacking the CC domain and proving orthologous to full gene 11 327 (CC-NB-LRR). Several synonymous mutations were identified on gene 4 and gene 16 in Cima 328 Viola (eggplant) as well as on tomato genes 8 and 9.

\section{Discussion}

331 The plant kingdom exhibits a large variation in PRG repertories among species but also among 332 single individuals (Shao et al. 2016). In our scanning of eggplant (Nakate-Shinkuro) genome 333 showed more or less the same number of tomato PRGs. By contrast, the PRGs of pepper Zunla-1 334 was contracted respect that pepper CM334 genome (Kim et al. 2014), in terms of NLRs and RLKs. 
335 Genotype loci rearrangements could occur in response to specific phytopathogens. Indeed, CM334 336 pepper is resistant to Phytophthora spp. and potyviruses, whereas Zunla-1 is resistant to Fusarium 337 wilt, Phytophthora spp. and Anthracnose (Qin et al. 2014). The variation in PRG number observed 338 in Solanaceae was also found in other taxa, such as Rosaceae (Jia et al. 2015), Graminaceae (Li et 339 al. 2010), Brassicaceae (Peele et al. 2014) and Fabaceae (Shao et al. 2014).

340 In our analysis the highest NLR concentration in pepper was evidenced on chromosome 5, that 341 characterized by presence of QTL for resistance to Phytophthora capsici (Rehrig et al. 2014), whilst 342 the eggplant genome showed the highest concentration of NLR genes on chromosome 11. On this 343 chromosome in tomato, the I2 gene is located, as are other important resistant gene loci. The 344 approach involving target-sequencing and co-localization with candidate $R$-genes may help to 345 identify putative genes for major diseases also in this species (Andolfo et al. 2013b).

346 Our results confirm that most Solanaceae PRGs tend to be physically clustered. However, to 347 explore the clustering tendency of such genes in several species it was necessary to perform a first 348 analysis with a dynamic setting in order to identify the most suitable method. Indeed, the 349 partitioning of genes into clusters could be hampered by genome architecture, including gene 350 density and gene order (Hoberman and Durand 2005).

351 In some studies, following an ordinal data strategy, a locus with two or more PRGs separated by a 352 number of non-PR genes (Richly et al. 2002, Luo et al. 2012) was identified as a cluster. In other 353 studies, a gene cluster was defined as a physical region that contains more than three or more genes 354 within $200 \mathrm{~Kb}$ or less (Holub 2001). We noted that by looking at least for three adjacent PRGs of $3550.5 \mathrm{Mb}$ in tomato and of $1 \mathrm{Mb}$ in pepper most well-known Solanaceae clusters were identified. The 356 task became more challenging when homologous regions were scrambled by rearrangement events 357 that modified the global genome architecture (Joshi and Nayak 2013). Therefore, we combined the 358 results obtained by using different methods to refine the annotation for size and number of genes 359 included in a cluster because the differences in the size and organisation of the two genomes 360 analysed made the comparison difficult. 
361 The size of $R$-gene clusters can vary significantly, from a few genes to several hundred genes, e.g. 362 Ve (Kawchuk et al. 2001) and Dm3 loci (Meyers et al. 1998). Most isolated resistance genes 363 occurring in clusters evidenced genome rearrangement that could be triggered by plant-pathogen 364 interaction (Spoel and Dong 2012). Recently, it was observed that increased pathogen pressure 365 induces epigenetic changes and promotes PRGs rearrangements (Molinier et al. 2006, Boyko et al. 366 2007, Alvarez et al. 2010). Indeed, the PRGs clusters play a leading role in new functional 367 resistance gene generation, since they represented a localized island of genetic variability in the 368 plant genome.

369 Orthology prediction analysis performed by comparing tomato, eggplant and pepper proteomes 370 evidenced more than 1000 pathogen recognition orthologues and related paralogues conserved 371 across the three cultivated Solanaceae spp. Some cloned tomato $R$-genes showed a putative 372 orthologue in pepper and eggplant, whilst other tomato PRGs were shared just with one species. 373 Merging orthology-related data and cluster data, we confirmed that PRGs comprise one of the most 374 plastic gene families in plants, associated with gene loss, gene conservation and gene clustering 375 (Zhang et al. 2014). Tomato chromosome 4 showed the highest number of conserved PRG clusters 376 even if some clusters were fragmented into different chromosomes in other species (Destefanis et 377 al. 2015). The putative Gpa2 locus in tomato, located on chromosome 12, shares an orthologous 378 relationship with two clusters located on chromosome 9 in pepper. PRG clusters on tomato 379 chromosome 9, including genes Sw5 and Tm2, showed orthologous clustering on pepper 380 chromosome 3 (Grube et al. 2000, Djian-Caporalino et al. 2007), where some genes involved in 381 resistance to viruses are located (Caranta et al. 1997).

382 Targeted capture sequencing allowed the detection of a big set of variations in genes located in 383 important resistance loci. Polymorphisms in the genomic region containing $R$-genes were 384 pronounced in several species (McHale et al. 2012, González et al. 2013). This technique displayed 385 its usefulness for sequencing large genomic regions, offering a simple method to analyse gene 386 polymorphism in a relatively efficient and economic manner (Grover et al. 2012). The sequenced 
387

388

389

390

391

392

393

394

395

396

397

398

399

400

401

402

403

404

405

406

407

408

409

410

411

syntenic regions in eggplant and pepper were larger than those in tomato, possibly due to the difference in genomic size reported for the species analysed (Tomato and Consortium 2012, Qin et al. 2014, Hirakawa et al. 2014). In particular, pepper showed a massive genomic insertion of transposable elements (Kim et al. 2014). Moreover, a lower number of reads was mapped in eggplant since its genome was not assembled in pseudomolecules. In general, the efficiency of target sequencing was similar to that observed in cross-species microarray experiments (Bar-Or et al. 2007, Lu et al. 2009, Nazar et al. 2010). The highest number of variants was obtained in $S$. peruvianum, confirming the level of polymorphism reported in the literature for this species (Aflitos et al. 2014).

The cataloguing of genes and the concerted use of genomic information (clustering tendency; orthology relationship and variant detection) showed to be a valuable strategy for identifying important genes or alleles and for exchanging information related to coding protein function across plant species. Comparative analysis of two selected PRG loci showed a high level of genome rearrangement (gene losses, duplicated genes, genome shuffling and transposable element insertions). PRG polymorphisms (SNPs, IN/DEL, domain loss or insertions) that can play an important role in gene recombination (Baumgarten et al. 2003, Meyers et al. 2003, McHale et al. 2012, Sanseverino and Ercolano 2012). Even if the mechanisms underlying enhanced recombination at these loci have not been clearly established, pathogen recognition protein structure changes can have a great impact in specific disease response (Wang et al. 1998, Zhang et al. 2004, Nandety et al. 2013). PRG architecture seems to be modified by the interplay of large-scale gene organisation that determines global conservation of locus order genome-wide and extensive local genome rearrangements mediated by tandem duplication, transposons and other shuffling elements that lead to distinct local arrangements (Zhang et al. 2014, Aversano et al. 2015). Regions including genes involved in defence responses have been shown to be hot-spots of genomic variability across genomes (Spoel and Dong 2012). Extant local arrangements of Solanaceae pathogen recognition 
412 genes within a genome are indicative of biological and environmental factors influencing genotype 413 adaptation, and have significant influence on phenotypic resistance diversity (Aversano et al. 2015).

\section{Funding}

This work was supported by the Italian Ministry of University and Research (GenHORTH project).

\section{Conflict of Interest Statement}

The authors declare that the research was conducted in the absence of any commercial or financial relationships that could be construed as a potential conflict of interest.

\section{Acknowledgments}

We thank Prof. Luigi Frusciante for his useful and constructive comments that contributed to improving the manuscript.

427

428

\section{References}

Aflitos, S., Schijlen, E., de Jong, H., de Ridder, D., Smit, S., Finkers, R., Wang, J., Zhang, G., Li, N., Mao, L., Bakker, F., Dirks, R., Breit, T., Gravendeel, B., Huits, H., Struss, D., Swanson-Wagner, R., van Leeuwen, H., van Ham, R.C.H.J., Fito, L., Guignier, L., Sevilla, M., Ellul, P., Ganko, E., Kapur, A., Reclus, E., de Geus, B., van de Geest, H., Hekkert, B.T.L., van Haarst, J., Smits, L., Koops, A., Sanchez-Perez, G., van Heusden, A.W., Visser, R., Quan, Z., Min, J., Liao, L., Wang, X., Wang, G., Yue, Z., Yang, X., Xu, N., Schranz, E., Smets, E., Vos, R., Rauwerda, J., Ursem, R., Schuit, C., Kerns, M., van den Berg, J., Vriezen, W., Janssen, A., Datema, E., Jahrman, T., Moquet, F., Bonnet, J., and Peters, S. 2014. Exploring genetic variation in the tomato (Solanum section Lycopersicon) clade by 
438

439

440

441

442

443

444

445

446

447

448

449

450

451

452

453

454

455

456

457

458

459

460

461

462

463

464

465

whole-genome sequencing. Plant J. (January): 136-148. doi:10.1111/tpj.12616.

Alexeyenko, A., Tamas, I., Liu, G., and Sonnhammer, E.L.L. 2006. Automatic clustering of orthologs and inparalogs shared by multiple proteomes. In Bioinformatics. doi:10.1093/bioinformatics/btl213.

Alvarez, M.E., Nota, F., and Cambiagno, D. a. 2010. Epigenetic control of plant immunity. Mol. Plant Pathol. 11(4): 563-576. doi:10.1111/j.1364-3703.2010.00621.x.

Andolfo, G., Jupe, F., Witek, K., Etherington, G.J., Ercolano, M.R., and Jones, J.D.G. 2014. Defining the full tomato NB-LRR resistance gene repertoire using genomic and cDNA RenSeq. BMC Plant Biol. 14(1): 120. doi:10.1186/1471-2229-14-120.

Andolfo, G., Sanseverino, W., Aversano, R., Frusciante, L., and Ercolano, M.R. 2013a. Genome-wide identification and analysis of candidate genes for disease resistance in tomato. Mol. Breed. 33(1): 227233. doi:10.1007/s11032-013-9928-7.

Andolfo, G., Sanseverino, W., Rombauts, S., Van de Peer, Y., Bradeen, J.M., Carputo, D., Frusciante, L., and Ercolano, M.R. 2013b. Overview of tomato (Solanum lycopersicum) candidate pathogen recognition genes reveals important Solanum R locus dynamics. New Phytol. 197(1): 223-37. doi:10.1111/j.1469-8137.2012.04380.x.

Aversano, R., Contaldi, F., Ercolano, M.R., Grosso, V., Iorizzo, M., Tatino, F., Xumerle, L., Dal Molin, A., Avanzato, C., Ferrarini, A., Delledonne, M., Sanseverino, W., Cigliano, R.A., Capella-Gutierrez, S., Gabaldón, T., Frusciante, L., Bradeen, J.M., and Carputo, D. 2015. The Solanum commersonii Genome Sequence Provides Insights into Adaptation to Stress Conditions and Genome Evolution of Wild Potato Relatives. In The Plant Cell. doi:10.1105/tpc.114.135954.

Bar-Or, C., Czosnek, H., and Koltai, H. 2007. Cross-species microarray hybridizations: a developing tool for studying species diversity. doi:10.1016/j.tig.2007.02.003.

Baumgarten, A., Cannon, S., Spangler, R., and May, G. 2003. Genome-level evolution of resistance genes in Arabidopsis thaliana. Genetics 165(1): 309-319.

Boyko, A., Kathiria, P., Zemp, F.J., Yao, Y., Pogribny, I., and Kovalchuk, I. 2007. Transgenerational changes in the genome stability and methylation in pathogen-infected plants: (Virus-induced plant genome instability). Nucleic Acids Res. 35(5): 1714-1725. doi:10.1093/nar/gkm029.

Camacho, C., Coulouris, G., Avagyan, V., Ma, N., Papadopoulos, J., Bealer, K., and Madden, T.L. 2009. 
466

467

468

469

470

471

472

473

474

475

476

477

478

479

480

481

482

483

484

BLAST plus: architecture and applications. BMC Bioinformatics 10(421): 1. doi:Artn 421 \nDoi 10.1186/1471-2105-10-421.

Caranta, C., Lefebvre, V., and Palloix, A. 1997. Polygenic Resistance of Pepper to Potyviruses Consists of a Combination of Isolate-Specific and Broad-Spectrum Quantitative Trait Loci. Mol. Plant-Microbe Interact. 10(7): 872-878. doi:10.1094/MPMI.1997.10.7.872.

Cingolani, P., Platts, A., Wang, L.L., Coon, M., Nguyen, T., Wang, L., Land, S.J., Lu, X., and Ruden, D.M. 2012. A program for annotating and predicting the effects of single nucleotide polymorphisms, SnpEff: SNPs in the genome of Drosophila melanogaster strain w 1118; iso-2; iso-3. Fly (Austin). 6(2): 80-92. doi:10.4161/fly.19695.

Coppe, A., Danieli, G.A., and Bortoluzzi, S. 2006. REEF: searching REgionally Enriched Features in genomes. BMC Bioinformatics 7(1): 453. doi:10.1186/1471-2105-7-453.

Destefanis, M., Nagy, I., Rigney, B., Bryan, G.J., McLean, K., Hein, I., Griffin, D., and Milbourne, D. 2015. A disease resistance locus on potato and tomato chromosome 4 exhibits a conserved multipartite structure displaying different rates of evolution in different lineages. BMC Plant Biol. 15: 255. doi:10.1186/s12870-015-0645-8.

Djian-Caporalino, C., Fazari, A., Arguel, M.J., Vernie, T., VandeCasteele, C., Faure, I., Brunoud, G., Pijarowski, L., Palloix, A., Lefebvre, V., and Abad, P. 2007. Root-knot nematode (Meloidogyne spp.) Me resistance genes in pepper (Capsicum annuum L.) are clustered on the P9 chromosome. Theor. Appl. Genet. 114(3): 473-486. doi:10.1007/s00122-006-0447-3.

Ercolano, M.R., Sanseverino, W., Carli, P., Ferriello, F., and Frusciante, L. 2012. Genetic and genomic approaches for R-gene mediated disease resistance in tomato: Retrospects and prospects. Plant Cell Rep. 31: 973-985. doi:10.1007/s00299-012-1234-z.

Fernandez-Pozo, N., Menda, N., Edwards, J.D., Saha, S., Tecle, I.Y., Strickler, S.R., Bombarely, A., FisherYork, T., Pujar, A., Foerster, H., Yan, A., and Mueller, L.A. 2015. The Sol Genomics Network (SGN)from genotype to phenotype to breeding. Nucleic Acids Res. 43(D1): D1036-D1041. doi:10.1093/nar/gku1195.

Gasc, C., Peyretaillade, E., and Peyret, P. 2016. Sequence capture by hybridization to explore modern and ancient genomic diversity in model and nonmodel organisms. Nucleic Acids Res. (8): gkw309-. 
494

495

496

497

498

499

500

501

502

503

504

505

506

507

508

509

510

511

512

513

514

515

516

517

518

519

520

521

doi:10.1093/nar/gkw309.

González, V.M., Aventín, N., Centeno, E., and Puigdomènech, P. 2013. High presence/absence gene variability in defense-related gene clusters of Cucumis melo. BMC Genomics 14: 782. doi:10.1186/1471-2164-14-782.

Grover, C.E., Salmon, A., and Wendel, J.F. 2012. Targeted sequence capture as a powerful tool for evolutionary analysis. Am. J. Bot. 99(2): 312-319. doi:10.3732/ajb.1100323.

Grube, R.C., Radwanski, E.R., and Jahn, M. 2000. Comparative genetics of disease resistance within the solanaceae. Genetics 155(2): 873-887.

Hirakawa, H., Shirasawa, K., Miyatake, K., Nunome, T., Negoro, S., Ohyama, A., Yamaguchi, H., Sato, S., Isobe, S., Tabata, S., and Fukuoka, H. 2014. Draft Genome Sequence of Eggplant (Solanum melongena L.): the Representative Solanum Species Indigenous to the Old World. DNA Res.: 1-12. doi:10.1093/dnares/dsu027.

Hoberman, R., and Durand, D. 2005. The Incompatible Desiderata of Gene Cluster Properties. Proc. RECOMB 2005 Int. Work. Comp. Genomics, RCG 2005 3678: 73-87.

Hoberman, R., Sankoff, D., and Durand, D. 2005. The statistical significance of max-gap clusters. Comp. Genomics: 55-71. Available from http://www.springerlink.com/index/VQQN6C6ECN9T0NM0.pdf.

Holub, E.B. 2001. The arms race is ancient history in Arabidopsis, the wildflower. Nat. Rev. Genet. 2(7): 516-527. doi:10.1038/35080508.

Jia, Y., Yuan, Y., Zhang, Y., Yang, S., and Zhang, X. 2015. Extreme expansion of NBS-encoding genes in Rosaceae. BMC Genet. 16: 48. ??? doi:10.1186/s12863-015-0208-x.

Jones, P., Binns, D., Chang, H.Y., Fraser, M., Li, W., McAnulla, C., McWilliam, H., Maslen, J., Mitchell, A., Nuka, G., Pesseat, S., Quinn, A.F., Sangrador-Vegas, A., Scheremetjew, M., Yong, S.Y., Lopez, R., and Hunter, S. 2014. InterProScan 5: Genome-scale protein function classification. Bioinformatics 30(9): 1236-1240. doi:10.1093/bioinformatics/btu031.

Joshi, R.K., and Nayak, S. 2013. Perspectives of genomic diversification and molecular recombination towards R-gene evolution in plants. Physiol. Mol. Biol. Plants 19(1): 1-9. doi:10.1007/s12298-012$0138-2$

Katoh, K., and Standley, D.M. 2013. MAFFT multiple sequence alignment software version 7: 
Improvements in performance and usability. Mol. Biol. Evol. 30(4): 772-780. doi:10.1093/molbev/mst010.

Kawchuk, L.M., Hachey, J., Lynch, D.R., Kulcsar, F., van Rooijen, G., Waterer, D.R., Robertson, a, Kokko, E., Byers, R., Howard, R.J., Fischer, R., and Prufer, D. 2001. Tomato Ve disease resistance genes encode cell surface-like receptors. Proc. Natl. Acad. Sci. U. S. A. 98(11): 6511-5. doi:10.1073/pnas.091114198.

Kearse, M., Moir, R., Wilson, A., Stones-Havas, S., Cheung, M., Sturrock, S., Buxton, S., Cooper, A., Markowitz, S., Duran, C., Thierer, T., Ashton, B., Meintjes, P., and Drummond, A. 2012. Geneious Basic: An integrated and extendable desktop software platform for the organization and analysis of sequence data. Bioinformatics 28(12): 1647-1649. doi:10.1093/bioinformatics/bts199.

Kim, S., Park, M., Yeom, S.-I., Kim, Y.-M., Lee, J.M., Lee, H.-A., Seo, E., Choi, J., Cheong, K., Kim, K.-T., Jung, K., Lee, G.-W., Oh, S.-K., Bae, C., Kim, S.-B., Lee, H.-Y., Kim, S.-Y., Kim, M.-S., Kang, B.-C., Jo, Y.D., Yang, H.-B., Jeong, H.-J., Kang, W.-H., Kwon, J.-K., Shin, C., Lim, J.Y., Park, J.H., Huh, J.H., Kim, J.-S., Kim, B.-D., Cohen, O., Paran, I., Suh, M.C., Lee, S.B., Kim, Y.-K., Shin, Y., Noh, S.J., Park, J., Seo, Y.S., Kwon, S.-Y., Kim, H. a, Park, J.M., Kim, H.-J., Choi, S.-B., Bosland, P.W., Reeves, G., Jo, S.-H., Lee, B.-W., Cho, H.-T., Choi, H.-S., Lee, M.-S., Yu, Y., Do Choi, Y., Park, B.S., van Deynze, A., Ashrafi, H., Hill, T., Kim, W.T., Pai, H.-S., Ahn, H.K., Yeam, I., Giovannoni, J.J., Rose, J.K.C., Sørensen, I., Lee, S.-J., Kim, R.W., Choi, I.-Y., Choi, B.-S., Lim, J.-S., Lee, Y.-H., and Choi, D. 2014. Genome sequence of the hot pepper provides insights into the evolution of pungency in Capsicum species. Nat. Genet. 46(3): 270-8. doi:10.1038/ng.2877.

Krzywinski, M., Schein, J., Birol, I., Connors, J., Gascoyne, R., Horsman, D., Jones, S.J., and Marra, M.A. 2009. Circos: An information aesthetic for comparative genomics. Genome Res. 19(9): 1639-1645. doi:10.1101/gr.092759.109.

Li, H., and Durbin, R. 2009. Fast and accurate short read alignment with Burrows-Wheeler transform. Bioinformatics 25(14): 1754-1760. doi:10.1093/bioinformatics/btp324.

Li, J., Ding, J., Zhang, W., Zhang, Y., Tang, P., Chen, J.Q., Tian, D., and Yang, S. 2010. Unique evolutionary pattern of numbers of gramineous NBS-LRR genes. Mol. Genet. Genomics 283(5): 427 438. doi:10.1007/s00438-010-0527-6. 
550 Lu, Y., Huggins, P., and Bar-Joseph, Z. 2009. Cross species analysis of microarray expression data. 551 Bioinformatics 25(12): 1476-1483. doi:10.1093/bioinformatics/btp247.

552 Luo, S., Zhang, Y., Hu, Q., Chen, J., Li, K., Lu, C., Liu, H., Wang, W., and Kuang, H. 2012. Dynamic 553 Nucleotide-Binding Site and Leucine-Rich Repeat-Encoding Genes in the Grass Family. Plant Physiol. 159(1): 197-210. doi:10.1104/pp.111.192062.

McHale, L.K., Haun, W.J., Xu, W.W., Bhaskar, P.B., Anderson, J.E., Hyten, D.L., Gerhardt, D.J., Jeddeloh, J.A., and Stupar, R.M. 2012. Structural variants in the soybean genome localize to clusters of biotic stress-response genes. Plant Physiol. 159(4): 1295-308. doi:10.1104/pp.112.194605.

Meyers, B.C., Chin, D.B., Shen, K. a, Sivaramakrishnan, S., Lavelle, D.O., Zhang, Z., and Michelmore, R.W. 1998. The major resistance gene cluster in lettuce is highly duplicated and spans several megabases. Plant Cell 10(11): 1817-1832. doi:http://www.plantcell.org/content/10/11/1817.short.

Meyers, B.C., Kozik, A., Griego, A., Kuang, H., and Michelmore, R.W. 2003. Genome-wide analysis of NBS-LRR - encoding genes in Arabidopsis. Plant Cell 15(April): 809-834. doi:10.1105/tpc.009308.During.

Molinier, J., Ries, G., Zipfel, C., and Hohn, B. 2006. Transgeneration memory of stress in plants. Nature 442(7106): 1046-1049. doi:10.1038/nature05022.

Nandety, R.S., Caplan, J.L., Cavanaugh, K., Perroud, B., Wroblewski, T., Michelmore, R.W., and Meyers, B.C. 2013. The role of TIR-NBS and TIR-X proteins in plant basal defense responses. Plant Physiol. 162(3): 1459-72. doi:10.1104/pp.113.219162.

Nazar, R.N., Chen, P., Dean, D., and Robb, J. 2010. DNA chip analysis in diverse organisms with unsequenced genomes. Mol. Biotechnol. 44(1): 8-13. doi:10.1007/s12033-009-9212-6.

Peele, H.M., Guan, N., Fogelqvist, J., and Dixelius, C. 2014. Loss and retention of resistance genes in five species of the Brassicaceae family. BMC Plant Biol. 14(Cc): 298. doi:10.1186/s12870-014-0298-z.

Qin, C., Yu, C., Shen, Y., Fang, X., Chen, L., Min, J., Cheng, J., Zhao, S., Xu, M., Luo, Y., Yang, Y., Wu, Z., Mao, L., Wu, H., Ling-Hu, C., Zhou, H., Lin, H., González-Morales, S., Trejo-Saavedra, D.L., Tian, H., Tang, X., Zhao, M., Huang, Z., Zhou, A., Yao, X., Cui, J., Li, W., Chen, Z., Feng, Y., Niu, Y., Bi, S., Yang, X., Li, W., Cai, H., Luo, X., Montes-Hernández, S., Leyva-González, M. a, Xiong, Z., He, X., Bai, L., Tan, S., Tang, X., Liu, D., Liu, J., Zhang, S., Chen, M., Zhang, L., Zhang, L., Zhang, Y., 
578

579

580

581

582

583

584

585

586

587

588

589

590

591

592

593

594

595

596

597

598

599

600

601

602

603

604

605

Liao, W., Zhang, Y., Wang, M., Lv, X., Wen, B., Liu, H., Luan, H., Zhang, Y., Yang, S., Wang, X., Xu, J., Li, X., Li, S., Wang, J., Palloix, A., Bosland, P.W., Li, Y., Krogh, A., Rivera-Bustamante, R.F., Herrera-Estrella, L., Yin, Y., Yu, J., Hu, K., and Zhang, Z. 2014. Whole-genome sequencing of cultivated and wild peppers provides insights into Capsicum domestication and specialization. Proc. Natl. Acad. Sci. U. S. A. 111(14): 5135-40. doi:10.1073/pnas.1400975111.

Rehrig, W.Z., Ashrafi, H., Hill, T., Prince, J., and Van Deynze, A. 2014. CaDMRl Cosegregates with QTL Pc5.1 for Resistance to in Pepper (Capsicum annuum). Plant Genome 7(2): 1-12. doi:10.3835/plantgenome2014.03.0011.

Remm, M., Storm, C.E., and Sonnhammer, E.L. 2001. Automatic clustering of orthologs and in-paralogs from pairwise species comparisons. J. Mol. Biol. 314(5): 1041-1052. doi:10.1006/jmbi.2000.5197.

Richly, E., Kurth, J., and Leister, D. 2002. Mode of amplification and reorganization of resistance genes during recent Arabidopsis thaliana evolution. Mol. Biol. Evol. 19(1): 76-84.

Sanseverino, W., and Ercolano, M.R. 2012. In silico approach to predict candidate R proteins and to define their domain architecture. BMC Res. Notes 5(1): 678. doi:10.1186/1756-0500-5-678.

Seo, E., Kim, S., Yeom, S.-I., and Choi, D. 2016. Genome-wide Comparative Analyses Reveal the Dynamic Evolution of Nucleotide-Binding Leucine-Rich Repeat Gene Family among Solanaceae Plants. Front. Plant Sci. 7(August): 1205. doi:10.3389/FPLS.2016.01205.

Shao, Z.-Q., Xue, J.-Y., Wu, P., Zhang, Y.-M., Wu, Y., Hang, Y.-Y., Wang, B., and Chen, J.-Q. 2016. Large-Scale Analyses of Angiosperm Nucleotide-Binding Site-Leucine-Rich Repeat Genes Reveal Three Anciently Diverged Classes with Distinct Evolutionary Patterns. Plant Physiol. 170(4): 20952109. doi:10.1104/pp.15.01487.

Shao, Z.-Q., Zhang, Y.-M., Hang, Y.-Y., Xue, J.-Y., Zhou, G.-C., Wu, P., Wu, X.-Y., Wu, X.-Z., Wang, Q., Wang, B., and Chen, J. 2014. Long-Term Evolution of Nucleotide-Binding Site-Leucine-Rich Repeat (NBS-LRR) Genes: Understandings Gained From and Beyond the Legume Family. Plant Physiol. 166(September): 217-234. doi:10.1104/pp.114.243626.

Spoel, S.H., and Dong, X. 2012. How do plants achieve immunity? Defence without specialized immune cells. Nat. Rev. Immunol. 12(2): 89-100. Nature Publishing Group. doi:10.1038/nri3141.

Steuernagel, B., Periyannan, S.K., Hernández-Pinzón, I., Witek, K., Rouse, M.N., Yu, G., Hatta, A., Ayliffe, 
606 M., Bariana, H., Jones, J.D.G., Lagudah, E.S., and Wulff, B.B.H. 2016. Rapid cloning of disease-

607

608

609

610

611

612

613

614

615

616

617

618

619

620

621

622

623

624

625

626

627

628

629

630

631

632

633

resistance genes in plants using mutagenesis and sequence capture. Nat. Biotechnol. (August 2015). doi:10.1038/nbt.3543.

Tamura, K., Stecher, G., Peterson, D., Filipski, A., and Kumar, S. 2013. MEGA6: Molecular evolutionary genetics analysis version 6.0. Mol. Biol. Evol. 30(12): 2725-2729. doi:10.1093/molbev/mst197.

Tomato, T., and Consortium, G. 2012. The tomato genome sequence provides insights into fleshy fruit $\begin{array}{lllll}\text { evolution. } & \text { Nature } & \text { 485(700): } & 635-41 . & \text { Available }\end{array}$ http://www.pubmedcentral.nih.gov/articlerender.fcgi?artid=3378239\&tool=pmcentrez\&rendertype=abs tract.

Vossen, J.H., Jo, K.R., and Vosman, B. 2014. Mining the genus solanum for increasing disease resistance. In Genomics of Plant Genetic Resources: Volume 2. Crop Productivity, Food Security and Nutritional Quality. Springer. pp. 27-46. doi:10.1007/978-94-007-7575-6_2.

Wang, G.-L., Ruan, D.-L., Song, W.-Y., Sideris, S., Chen, L., Pi, L.-Y., Zhang, S., Zhang, Z., Fauquet, C., Gaut, B.S., Whalen, M.C., and Ronald, P.C. 1998. Xa21D Encodes a Receptor-Like Molecule with a Leucine-Rich Repeat Domain That Determines Race-Specific Recognition and Is Subject to Adaptive Evolution. Plant Cell 10(5): 765. doi:10.2307/3870663.

Wang, Y., Diehl, A., Wu, F., Vrebalov, J., Giovannoni, J., Siepel, A., and Tanksley, S.D. 2008. Sequencing and comparative analysis of a conserved syntenic segment in the solanaceae. Genetics 180(1): 391-408. doi:10.1534/genetics.108.087981.

Wei, C., Chen, J., and Kuang, H. 2016. Dramatic Number Variation of R Genes in Solanaceae Species Accounted for by a Few $R$ Gene Subfamilies. PLoS One 11(2): e0148708. doi:10.1371/journal.pone.0148708.

Witek, K., Jupe, F., Witek, A.I., Baker, D., Clark, M.D., and Jones, J.D.G. 2016. Accelerated cloning of a potato late blight-resistance gene using RenSeq and SMRT sequencing. Nat. Biotechnol. (August 2015): 1-8. doi:10.1038/nbt.3540.

Yeaman, S. 2013. Genomic rearrangements and the evolution of clusters of locally adaptive loci. Proc. Natl. Acad. Sci. U. S. A. 110(19): E1743-51. doi:10.1073/pnas.1219381110.

Zhang, R., Murat, F., Pont, C., Langin, T., and Salse, J. 2014. Paleo-evolutionary plasticity of plant disease 
634 resistance genes. BMC Genomics 15(1): 187. BMC Genomics. doi:10.1186/1471-2164-15-187.

635 Zhang, Y., Dorey, S., Swiderski, M., Jones, J.D.G., Centre, J.I., and Lane, C. 2004. Expression of RPS4 in 636 tobacco induces an AvrRps4-independent HR that requires EDS1, SGT1 and HSP90. Plant J. 40(2):

637 213-24. doi:10.1111/j.1365-313X.2004.02201.x.

638 


\section{Tables}

641

642

643

Table 1. Results of identification of PRG clusters using Sliding window (window size: 0.5 and $1 \mathrm{Mb}$ ) and Max Gap analysis.

HEINZ 1706
2 GENES 3 GENES 4 GENES

Sliding window analysis $(0.5 \mathrm{M})$

\begin{tabular}{|c|c|c|c|c|c|c|}
\hline average $n$. genes for cluster & 5,6 & 6,1 & 6,9 & 4,3 & 5,3 & 9,3 \\
\hline n. of clusters & 66 & 61 & 50 & 147 & 101 & 59 \\
\hline n. of genes in cluster & 368 & 370 & 344 & 632 & 540 & 412 \\
\hline NB-ARC genes in cluster & 159 & 147 & 153 & 211 & 178 & 126 \\
\hline RLP genes in cluster & 83 & 80 & 67 & 162 & 134 & 112 \\
\hline RLK genes in cluster & 79 & 94 & 87 & 154 & 140 & 110 \\
\hline average lenght of clusters (bp) & 281917 & 314068 & 355599 & 255315 & 313651 & 393368 \\
\hline \multicolumn{7}{|c|}{ Sliding window analysis (1 Mb) } \\
\hline average $n$. genes for cluster & 8,1 & 8,1 & 8,1 & 4,6 & 6,5 & 8,1 \\
\hline n. of clusters & 39 & 45 & 47 & 106 & 91 & 62 \\
\hline n. of genes in cluster & 317 & 365 & 382 & 597 & 591 & 504 \\
\hline NB-ARC genes in cluster & 140 & 160 & 151 & 193 & 189 & 161 \\
\hline RLP genes in cluster & 56 & 80 & 84 & 148 & 151 & 128 \\
\hline RLK genes in cluster & 81 & 93 & 103 & 154 & 139 & 138 \\
\hline average lenght of clusters (bp) & 721002 & 829940 & 780434 & 510068 & 647393 & 818992 \\
\hline \multicolumn{7}{|l|}{ Max Gap analysis } \\
\hline average $n$. genes for cluster & 3,2 & 4,5 & 5,7 & 3,9 & 5,3 & 6,6 \\
\hline n. of clusters & 146 & 72 & 40 & 201 & 114 & 72 \\
\hline n. of genes in cluster & 471 & 323 & 227 & 778 & 604 & 478 \\
\hline NB-ARC genes in cluster & 192 & 142 & 100 & 250 & 205 & 164 \\
\hline RLP genes in cluster & 110 & 74 & 49 & 197 & 156 & 120 \\
\hline RLK genes in cluster & 112 & 72 & 54 & 206 & 150 & 121 \\
\hline average lenght of clusters (bp) & 67980 & 106576 & 120984 & 407856 & 510818 & 655767 \\
\hline
\end{tabular}


645 Table 2. PRG orthologous clusters identified by merging of max-gap (MG) and sliding-window (SW) results.

646

\section{HEINZ 1706 ZUNLA-1}

\begin{tabular}{|l|ll|}
\hline no. of clusters & 73 & 103 \\
no. of genes in cluster & 415 & 643 \\
average no. of genes per cluster & 5.7 & 3.9 \\
average length of clusters (bp) & 298.565 & 733.549 \\
NB-ARC genes in cluster & 171 & 209 \\
RLP genes in cluster & 96 & 163 \\
RLK genes in cluster & 104 & 170
\end{tabular}

647

648 Table 3. Gene variant categories detected by targeted sequencing in pathogen recognition genes. Downstream and 649 upstream variants located in coding sequences and their putative promoter regions $(2 \mathrm{~Kb}$ upstream the translation start 650 site).

S. lycopersicum var. Pyrella .

S. peruvianum 10543

S. melongena Cima Viola

C. annuum 1014

\begin{tabular}{l}
\hline Upstream \\
Codon_change \\
Frame_shift \\
Intron \\
Non_synonymous_coding \\
Splice_site_acceptor \\
Splice_site_donor \\
Splice_site_region \\
Stop_gained/lost \\
Synonymous_coding \\
Downstream \\
Total
\end{tabular}

\begin{tabular}{|llll|}
21 & 3121 & 25 & 101 \\
0 & 18 & 0 & 1 \\
1 & 14 & 0 & 1 \\
8 & 648 & 0 & 17 \\
5 & 1567 & 11 & 52 \\
0 & 2 & 0 & 0 \\
0 & 1 & 0 & 0 \\
0 & 17 & 0 & 1 \\
0 & 20 & 0 & 5 \\
2 & 980 & 19 & 13 \\
35 & 3080 & 25 & 52 \\
$\mathbf{7 2}$ & $\mathbf{9 4 6 8}$ & $\mathbf{8 0}$ & $\mathbf{2 4 3}$ \\
\hline
\end{tabular}


652

653

654

655

656

657

658

659

660

661

662

663

664

665

666

667

668

669

670

671

672

673

674

675

676

677

678

679

680

681

\section{Figure legends}

Figure 1. Chromosome distribution of main pathogen recognition protein classes (RLP: receptor-like protein, RLK: receptor-like kinase and NLR: nucleotide-binding leucine rich repeat) of $S$. melongena Nakate-Shinkuro (NAK) and $C$. annuum Zunla-1 (ZUN). For comparative propose we reported the number of PRGs identified in S. lycopersicum Heinz 1706 (HEI) for each chromosome by Andolfo et al. 2013.

Figure 2. Bar chart of Solanaceae resistance orthologous groups (ROGs). Three species (pepper, tomato and eggplant) were used to generate the diagram. The shared ROGs between pepper-tomato-eggplant, tomato-pepper, tomato-eggplant and pepper-eggplant in cyan, green, yellow and red bars were showm, respectively. The number of pathogen recognition genes (PRGs) of common groups for each plant species (HEI: tomato; NAK: eggplant; ZUN: pepper) is reported below the horizontal line.

Figure 3. Comparative map of conserved PRG loci identified in this study. External rings (A) represent tomato chromosomes (red), pepper chromosomes (orange) and eggplant chromosome (purple) that are reported on a common scale. Eggplant chromosomes were designed using assembled sequencing blocks (Methods). The location of Solanaceae cloned resistance genes is indicated by gene id on tomato chromosomes. B) Genomic location of detected NLR genes (red bars). C, D) Genomic location of RLP and RLK detected genes (green and blue bars, respectively). E) Genomic location of detected PRG clusters (black arrows). F) Internal arcs connect the PRG clusters that share at least one orthologous gene among all genomes (red), between pepper and tomato (grey), between tomato and eggplant (purple), between eggplant and pepper (yellow).

Figure 4 Reconstruction of the gene duplication history of target genomic region 4. (a) Schematic representation of postulated gene duplication events occurring in the genomic region. Detected gene variants are reported as green (low impact on coding gene) or yellow (medium impact on coding gene) ticks. Phylogenetic analysis performed using the maximum likelihood method, based on the general time reversible model, for homologous sequences of cytoplasmic (NLR; panel b) and transmembrane (RLP and RLK; panel c) receptor proteins. Bootstrap values are indicated above branches. (d) Multiple alignment of pepper, tomato and eggplant genomic sequences. We reported gene locus (green), the exons (yellow) and the transposable element (brown). Pepper region includes Capana11g001502 (12), Capana11g001503 (13) genes and a transposable element in the intergenic region while tomato (7) and eggplant (1) 
682 homologous genes lack any transposon insertion. Red rectangles display the most highly conserved sequences,

683 indicated as Region 1 (Pairwise Identity 82.4\%; Identical Sites 73,5\%), Region 2 (Pairwise Identity 100\%; Identical

684 Sites $100 \%$ ) and Region 3 (Pairwise Identity $79.3 \%$; Identical Sites 70,9\%).

685

686 Figure 5. Reconstruction of the gene duplication history of target genomic region 4. region 10. (a) Representation of 687 postulated duplication and of identified variants in green (low impact on coding gene) or in yellow (medium impact on 688 coding gene). Phylogenetic analysis performed on homologous sequences of cytoplasmic (NLR; panel b) and 689 transmembrane (RLP and RLK; panel c) receptor proteins. Bootstrap values are indicated above branches. (d) Multiple 690 alignment of pepper (13,14), tomato (11) and eggplant (3) sequences and for each genes, we reports: locus (green), 691 exons (yellow) and transposable element (brown). An insertion of transposable element on sequence of pepper gene 14 692 was evidenced. Red rectangles display highly conserved sequences, indicated as Region 1 (Pairwise Identity 78.3\%; 693 Identical Sites 64.4\% ), Region 2 (Pairwise Identity 89.6\%; Identical Sites 89.6\%) and Region 3 (Pairwise Identity $69475.8 \%$; Identical Sites 85.6\%).

695 


\section{Supplementary materials}

697

Supplementary tables legends:

699

Table S1. Classification of S. melongena and C. annuum pathogen recognition genes that encode domains similar to plant R proteins.

Table S2. Annotated PRGs list and their relative genomic positions. *The chromosome position of eggplant PRGs were assigned on the base of results reported in table S17 by Hirakawa et al. (2014)

705

Table S3. Resistance ortholog groups (ROGs) list. In the table for each identified PRGs, we reported plant species, cluster ID, ortholog confidence score, protein class and short name of R-gene homologue. *For the partial proteins the class was not reported (-).

Table S4. List of PRG clusters obtained from data merging of cluster prediction in pepper and tomato.

Table S5. Syntenic genomic regions sequenced in tomato, eggplant and pepper genomes. The regions length and the number of mapped reds are related to three reference genomes (S. lycopersicum_ Heinz 1706; S. melongena _NakateShinkuro; C. annuum Zunla-1). *Target regions used for microsynteny analysis.

Table S6. Detected variants (SNPs and InDel) of selected genomic regions for target sequencing experiment.

\section{Supplementary figures legends:}

719 Figure S1. Workflow of the targeted sequencing and variant-calling experiment.

Figure S2. Proportion of homozygous and heterozygous SNPs assessed in four species. Zygosity classes are colourcoded as indicated. Accession IDs and the percentage of SNPs are indicated on the $\mathrm{x}$ and $\mathrm{y}$ axes, respectively.

Figure S3 Proportion of DNA variant types assessed in the four species. Variant types are colour-coded as indicated. 


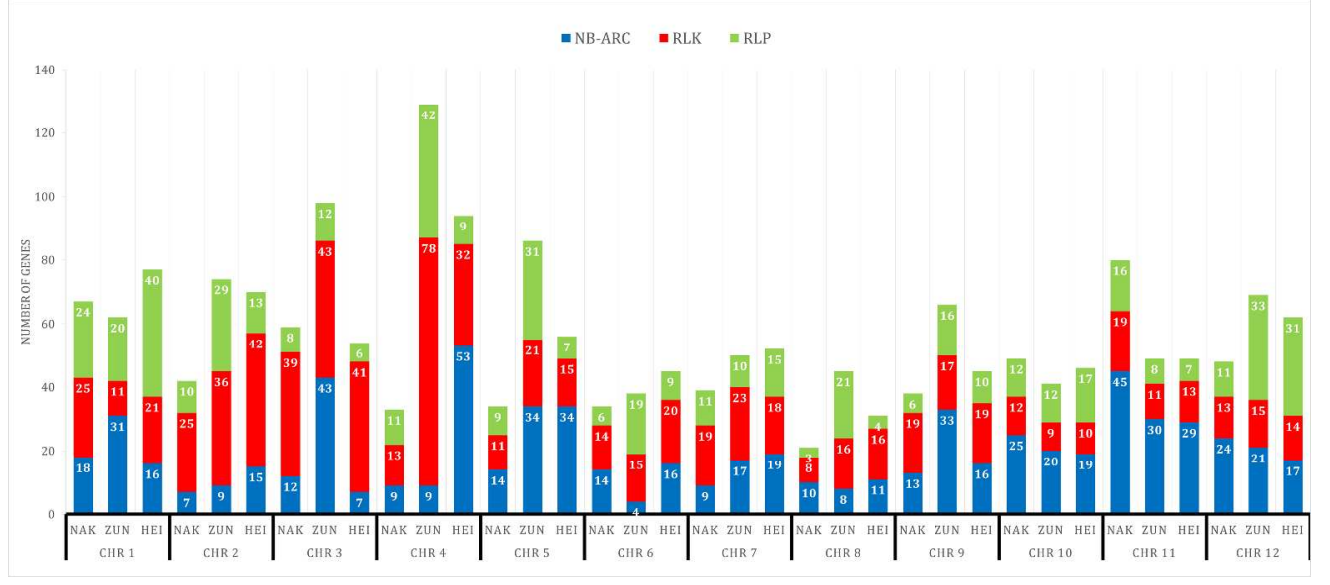

$1402 \times 623 \mathrm{~mm}(72 \times 72 \mathrm{DPI})$ 


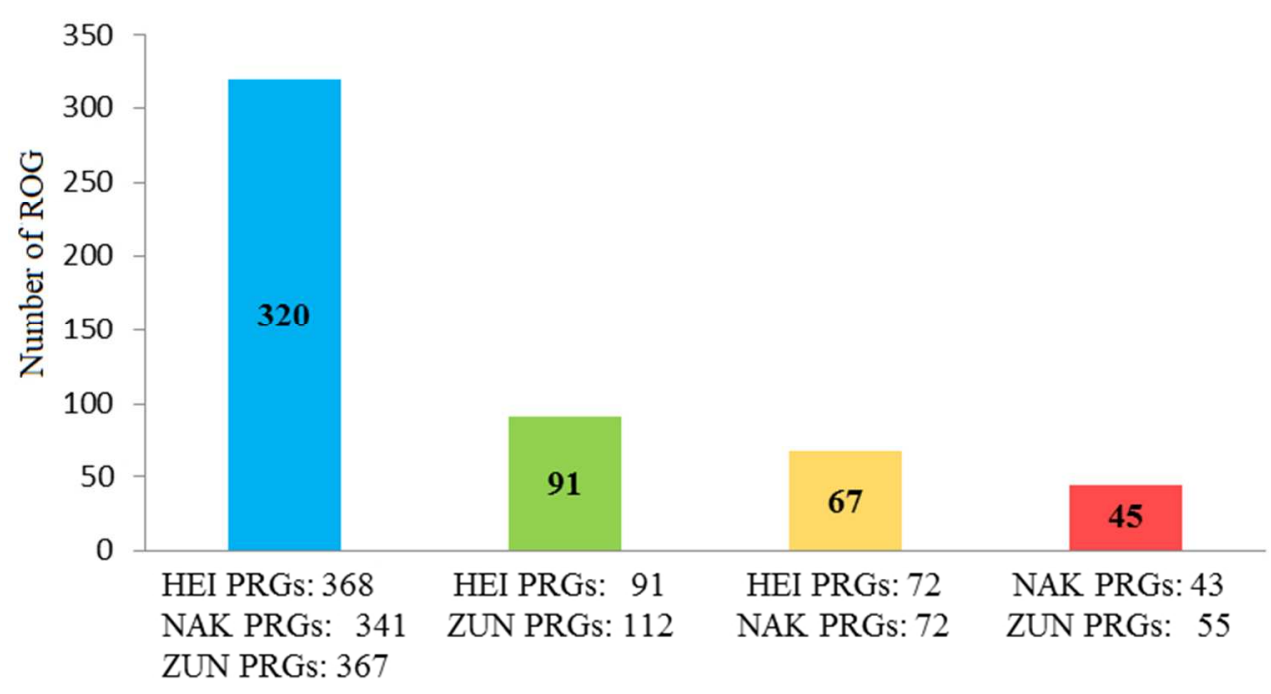

$213 \times 120 \mathrm{~mm}(96 \times 96$ DPI $)$ 


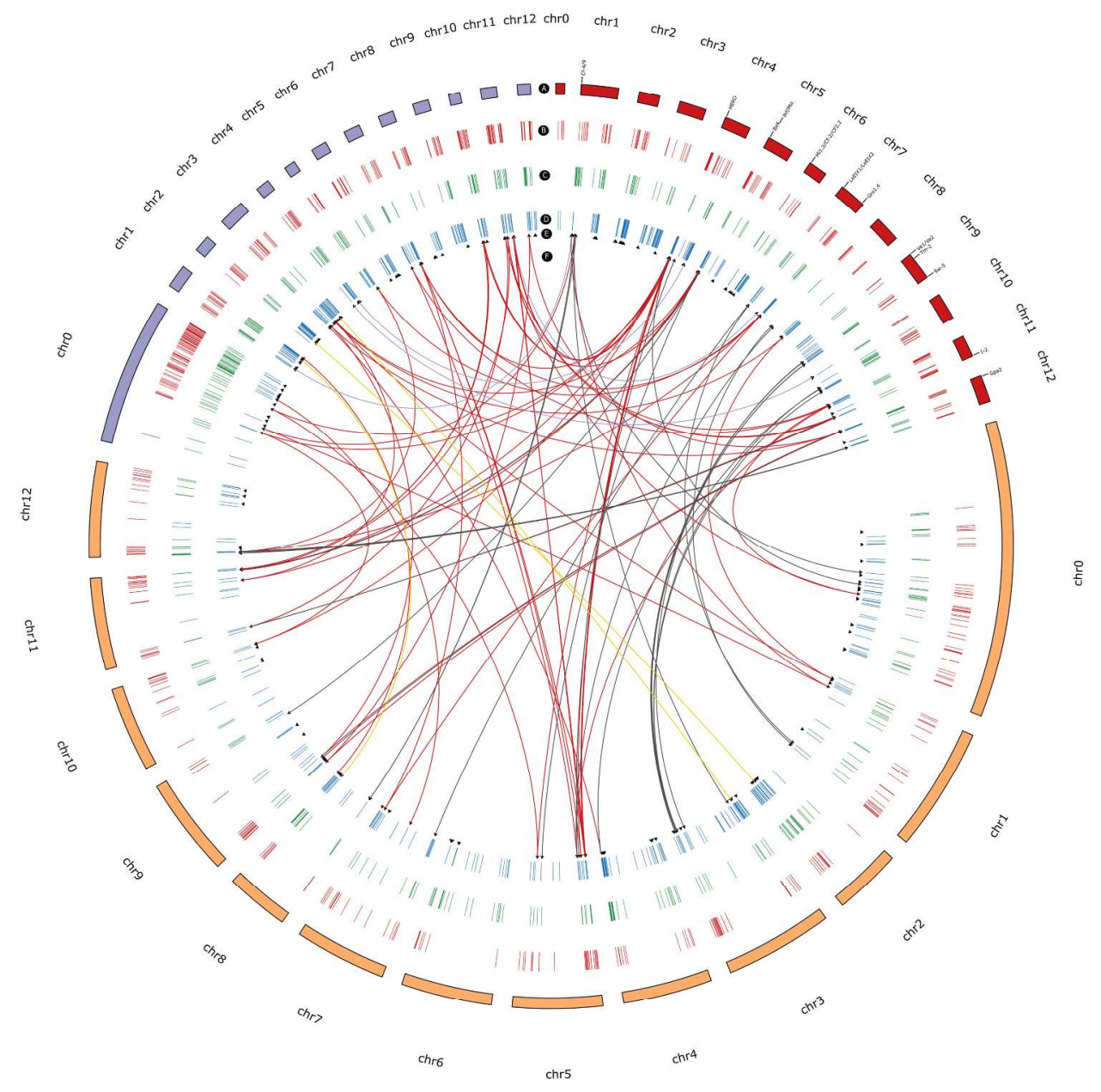

$116 \times 117 \mathrm{~mm}(600 \times 600 \mathrm{DPI})$ 


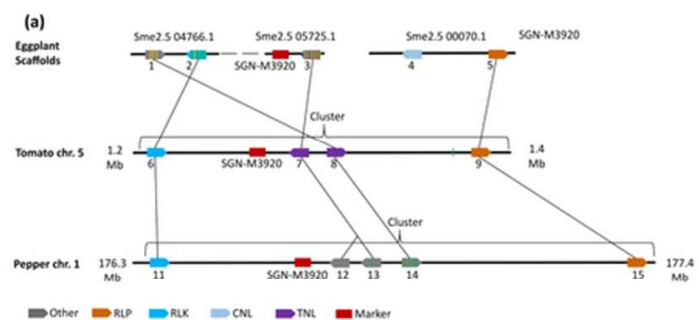

(b)
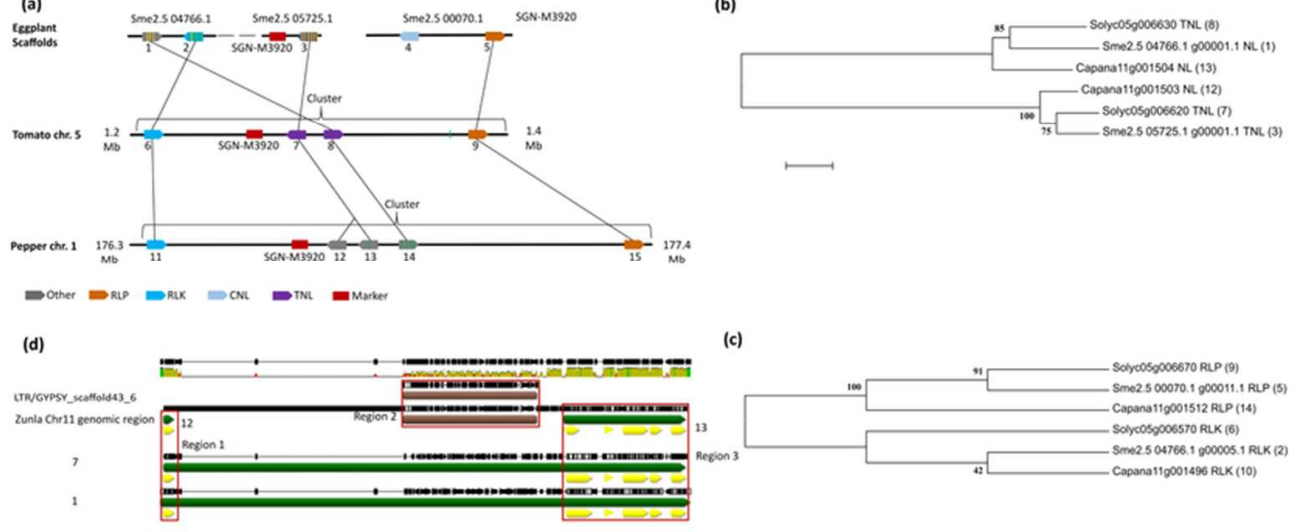

Figure 4

$35 \times 15 \mathrm{~mm}(600 \times 600$ DPI $)$ 

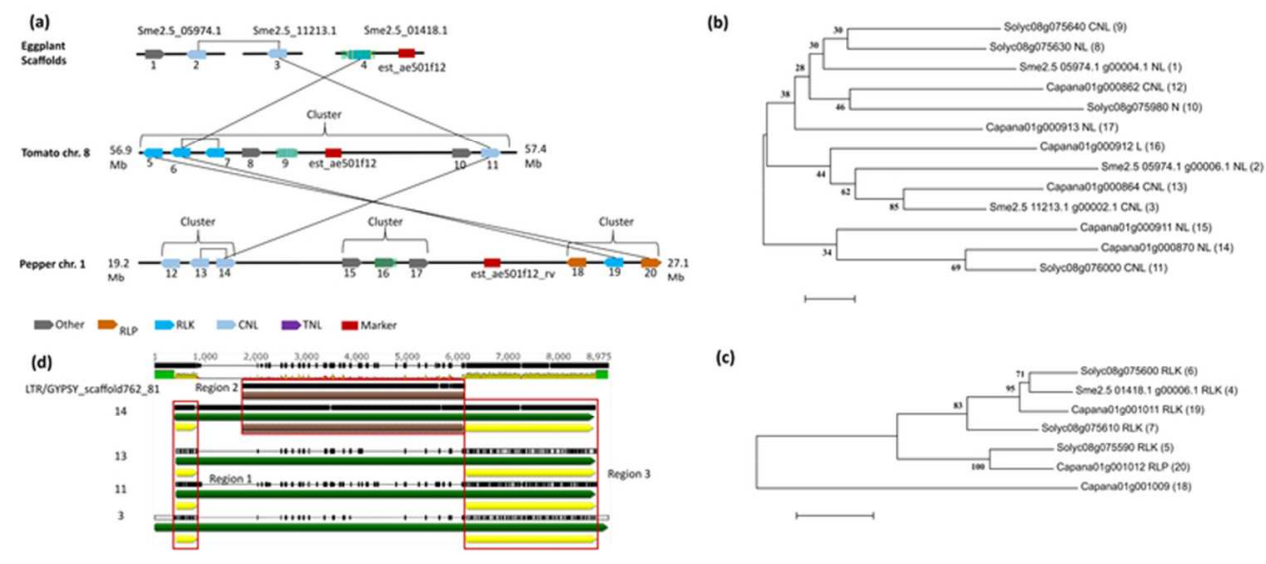

Figure 5

$35 \times 15 \mathrm{~mm}(600 \times 600 \mathrm{DPI})$ 